\title{
EVALUATING SERVICE QUALITY IN THE DURBAN FREIGHT TRANSPORTATION INDUSTRY
}

\author{
JEEVARATHNAM P. GOVENDER \\ KOOVENDHRAN NAIDU \\ govendej@dut.ac.za \\ Department of Marketing, Retail and Public Relations \\ Durban University of Technology
}

\begin{abstract}
This paper evaluates service quality in the Durban freight transportation industry, in which a high degree of competition exists. Previous measurements of service quality in the industry have been casual gauges, rather than a formalised process. This paper makes a contribution by examining the level of service quality, specifically from a tangibles, reliability and responsiveness perspective, thereby identifying service quality gaps which need to be closed, with a view to raising service quality levels in the industry. The SERVQUAL instrument has been used to measure service quality levels administered to 500 of the industry's active customers, i.e. organisations utilising the services of the freight transportation industry. The targeted respondents were managers responsible for logistics in their organisations. It was found that gaps existed between expectations and perceptions of service quality on 14 of the 15 measured items. Recommendations are made as to how the industry can improve its service quality levels.
\end{abstract}

\section{INTRODUCTION}

The Durban freight transportation industry is characterised by fierce competition posed by large national operators, medium-sized regional companies, and smaller local operators. In this context, service quality can be used as a beneficial tool in raising the competitiveness of operators. The worldwide trend towards service quality had its origins in the 1980s when businesses realised that a quality product in itself is not guaranteed to maintain competitive advantage (van der Wal, Pampalis \& Bond, 2002:233). Service quality is now being linked to increased profitability, customer satisfaction, competitive advantage, differentiation and a continual flow of value (Zeithaml, Bitner \& Gremler, 2006:19). Customers are now demanding higher standards of services. Therefore, customer satisfaction, customer value and service quality have become the primary focus of service organisations in today's customer era (Wang, Hing-Po \& Yang, 2004).

Clearly, measuring service quality can prove useful in enhancing the competitiveness of operators in this industry. Service quality in the transportation industry has been a key 
element in differentiating a company's product offerings from those of competitors. Owing to the seemingly standardised nature of the product, service quality becomes a key element in product differentiation. The aim of this paper, therefore, is to evaluate service quality in the Durban freight transportation industry. The targeted respondents for the study are managers of organisations responsible for logistics who utilise the services of the Durban freight transportation sector. The objectives will be achieved by measuring the levels of service quality in the industry using the SERVQUAL model, identifying the gaps in respect of the service quality dimensions, and testing for statistically significant relationships among the variables. The discussion comprises a literature review, followed by the problem statement, objectives and hypotheses. The research strategy is explained, the results of the empirical study are presented, and recommendations are made as to how service quality can be improved by operators in the Durban freight transportation industry.

\section{LITERATURE REVIEW}

\section{The meaning of 'service quality'}

There has been debate as to the best way to define service quality (Becket \& Brookes, 2006:124). Quality is viewed as the degree to which the service, the process and the service organisation can satisfy the customer's expectations (Brink \& Berndt, 2005:46-47). Putruzellis, D'Ugento and Romanazzi (2006:351) support the premise that higher service quality results in greater customer satisfaction. Therefore, satisfaction is based on the customer's expectations and perceptions of service quality (Ekinci, 2004:200). Woo and Ennew (2005:118) believe that service quality results from customers' comparisons of their expectations about a service encounter with their perceptions of the service encounter.

Zeithaml, et al. (2006:49) view expectations as beliefs about service delivery. These beliefs function as standards against which performance is evaluated. Customer expectations are essential to services marketers. These authors further elaborate that customer expectations are not stable and are, indeed, human perceptions based on verbal information, personal needs, experience and commercial information. Customers' perceptions are subjective assessments of the actual services. This relates to how customers perceive services; how they evaluate the quality of service received; whether they are satisfied and whether they have received good value. In essence, customers' perceptions are the way that people see something based on their experience. Each person's perception of a situation will vary. Perceptions are usually formed over a period of time and reflect the ways that one has been treated, his/her values, priorities, prejudices and sensitivity to others (Harris, 2003:16).

Dhurup, Singh and Surujlal (2006:42) explain that when a company performs a service carelessly, makes avoidable mistakes and fails to deliver on promises that it has made to attract customers, it unsettles the customers' confidence and compromises the company's chances of receiving a reputation for service excellence. 


\section{Dimensions of service quality}

Blose and Tankersley (2004:77) identify five dimensions of service quality. These are tangibles, responsiveness, reliability, empathy and assurance. For the purpose of this paper, the first three dimensions are analysed.

Tangibles refer to the physical facilities, professional appearance of staff and communication materials such as brochures. These are crucial to providing a total educational experience (Zeithaml, et al., 2006:120).

Blose and Tankersley (2004:78) believe that providing a service and meeting commitments on time according to the promised service date in a professional manner, will influence a customer's perception in an important way. The employees at the institution should perform to the desired service level correctly the first time. It also means the organisation keeps its promises within the specific time frame set out. If this delivery is done in a proper way, it will enhance the perceived quality of the customer (Brink \& Berndt, 2005:60).

Dale (2003:240) defines responsiveness as the willingness to assist customers and to provide prompt service on a continuous basis. Responsiveness is linked to the time period that customers have to wait for help, receive answers to queries or attention to problems as well as the ability to develop customised solutions for customers. Blose and Tankersley (2004:80) contend that, whether the interaction occurs face to face or telephonically, the degree to which the service personnel exhibit the ability to handle such matters effectively, and whether they care about attending to the customer's request, will undoubtedly impact on perceptions of service quality.

Jaiswal (2008:409) believes that reliability is the most important dimension of service quality attributes. Reliability improvements are at the heart of service quality enhancement efforts because unreliable service means promises not being met on the attributes that customers care about on the service received. If the main service is not performed reliably, customers may assume that the company is incompetent and may switch to another organisation.

\section{Analysing the gap between perceived service and expected service}

The gap between perceived service and expected service represents the difference between actual performance and the consumers' preconception of the service. This is also known as the service gap and provides a distinct indication of the level of service quality. The expected quality is what customers expect to receive from the company and the perceived service is what customers believe they received from the company. If customers receive less than what they expected, they are dissatisfied. Conversely, if perceived service is greater than expected service, the result is satisfaction (Kotler, Bowen \& Makens, 2006:435). 
Kotler, et al. (2006:152) argue that the most important gap is between the customers' expectations and their perceptions of the service quality actually delivered. Zeithaml, et al. (2006:41) concur with the aforementioned view by stating that, in order to manage service quality, it is important to manage the gaps between expectations and perceptions on the part of management, employers and customers. Mullins, Walker, Boyd and Larreche (2005:424) suggest that organisations must close these gaps in order to improve customer satisfaction and build long-term relationships.

\section{Service quality and customer satisfaction}

Fen and Lian (2007: 62) propose that, while customer satisfaction and service quality are two distinct concepts, these two constructs are closely correlated. Several studies in marketing literature have discovered positive relationships between service quality and customer satisfaction (Jaiswal, 2008:407).

Satisfaction is the customer's assessment of a product or service in terms of whether that product or service has met the customer's needs and expectations (Bruhn \& Georgi, 2006:443).

\section{PROBLEM STATEMENT, OBJECTIVES AND HYPOTHESES}

\section{Problem statement}

It becomes evident that service quality can play a significant role in enhancing the competitiveness of operators in the Durban freight transportation industry. The levels of service quality as expected and perceived by users (customers) in the industry are not clearly known. This paper therefore seeks to evaluate service quality levels among users in the Durban freight transportation industry.

\section{Objectives and hypotheses}

The objectives of this paper are:

- to ascertain the levels of service quality in terms of expectations and perceptions of service quality on the dimensions of tangibles, reliability and responsiveness

- to determine the gaps between the measures of expectations and perceptions of service quality on the dimensions of tangibles, reliability and responsiveness

- to measure the inter-correlations of the service quality dimensions in terms of expectations and perceptions

- to determine the relationship between selected biographical variables and the expectations and perceptions of service quality 
The following hypotheses are presented:

Regarding expectations of customers with respect to the service quality dimensions and industry:

- Null hypothesis ( $\mathrm{HO})$ : There is no significant difference between the expectations of customers with regard to the service quality dimensions and industry.

- Alternate hypothesis $(\mathrm{H} 1)$ : There is a significant difference between the expectations of customers with regard to the service quality dimensions and industry.

Regarding perceptions of customers with respect to the service quality dimensions and industry:

- Null hypothesis ( $\mathrm{HO})$ : There is no significant difference between the perceptions of customers with regard to the service quality dimensions and industry.

- Alternate hypothesis (H1): There is a significant difference between the perceptions of customers with regard to the service quality dimensions and industry.

\section{RESEARCH STRATEGY}

\section{Research approach}

The research constitutes a quantitative, descriptive, cross-sectional study, which investigates two main issues, viz. customer expectations and perceptions of service quality.

\section{Respondents}

The target population comprised the industry's customers who operate in three industries, namely. shipping, petrochemicals and manufacturing. Two significant industries, namely mining and forestry, were excluded because of their absence in this geographic region (the Durban area). Only active customers formed the target population, i.e. those who had transacted with the industry in the past six months.

A sample of 500 respondents was selected. To this end a judgmental sample of 20 large freight companies was chosen, from which 25 clients from each company were chosen using convenience sampling. Questionnaires were distributed to respondents via the 20 transport companies. These were intended to be completed by managers responsible for logistics at the respective organisations. The number of usable questionnaires that were returned totalled 440 .

\section{Measuring instrument}

The study used an adapted version of the SERVQUAL model which identifies gaps where a shortfall between expectation of service level and perception of actual service delivery may occur (Bruhn \& Georgi, 2006:31). Of the five dimensions that constitute the measurement of 
service quality, three dimensions were analysed, viz. tangibles, reliability and responsiveness. The remaining two dimensions (assurance and empathy) are excluded from this paper for two reasons: first, the findings with regard to these dimensions were not significant, and secondly, in the interest of not having an excessively long discussion. The service quality dimensions were measured using interval scaling, or more specifically, a 5-point Likert scale ranging from 'strongly disagree' to 'strongly agree'.

\section{Statistical analysis}

The Statistical Package for Social Sciences (SPSS), Version 16 was used to analyse the results. Non-parametric testing was conducted, considering that non-probability sampling was used; hence the underlying population distribution being unknown (Pallant, 2007:210). A comparison of means using Analysis of Variance (ANOVA) was conducted. A Spearman correlation analysis was undertaken in view of the data being ordinal in nature. The correlation co-efficients were interpreted as 0.21 to 0.40 being weak, 0.41 to 0.60 being moderate and 0.61 to 0.80 being strong, based on the guidelines provided by Shui, Hair, Bush and Ortinau (2009:555). The level of significance has been selected at 95\% ( $p \leq 0.05$ ).

\section{DISCUSSION}

The following section constitutes a discussion of the findings.

\section{Industry to which respondents belonged}

It emerged that of the 440 responses received, 242 were from the petrochemicals industry, 101 from the shipping industry and 97 from the manufacturing industry.

\section{Length of patronage}

Table 1 provides an indication of the number of years respondents have been customers to the industry. The majority of respondents were customers for between six and 15 years, with 23 respondents being customers for over 21 years.

Table 1: Length of patronage

\begin{tabular}{|l|c|c|}
\hline Period & $\mathbf{n}$ & $\mathbf{\%}$ \\
\hline Less than one year & 28 & 6 \\
\hline $1-5$ years & 82 & 19 \\
\hline $6-10$ years & 118 & 27 \\
\hline $11-15$ years & 138 & 31 \\
\hline $16-20$ years & 51 & 12 \\
\hline $21-25$ years & 10 & 2 \\
\hline Over 25 years & 13 & 3 \\
\hline Total & $\mathbf{4 4 0}$ & 100 \\
\hline
\end{tabular}




\section{Test for reliability}

Tests for inter-item consistency were conducted in respect of the items constituting the expectations and perceptions dimensions. A Cronbach's alpha value of 0.849 was computed for the expectations component and 0.870 for the perceptions component. Malhotra (2010:319) suggests that a Cronbach's alpha value of more than 0.6 is generally accepted as representing good reliability. The computed Cronbach's alpha value for this study therefore indicated a high level of reliability and internal consistency.

\section{Customer expectations and perceptions by dimension}

This section presents an analysis of the specific expectations versus perceptions for each of the three service quality dimensions.

\section{Tangibles: Expectations versus perceptions}

Figure 1 presents the items that constitute the tangibles dimension. Of the five items, resources and capacity were ranked the highest, both in terms of expectations and perceptions, with modern technology being indicated as the least important.

It emerged that the expectations and perceptions of the company having an attractive office were equal, hence no gap. This was the only dimension scoring equally for expectations and perceptions. It is noteworthy that respondents' perceptions exceeded expectations with regard to the industry having modern technology. This was the only item where perceptions exceeded expectations. The remaining items, viz. having adequate resources and capacity, having a professional appearance and the dress of staff being smart, showed a very small gap between expectations and perceptions, ranging from 0.02 to 0.2 .

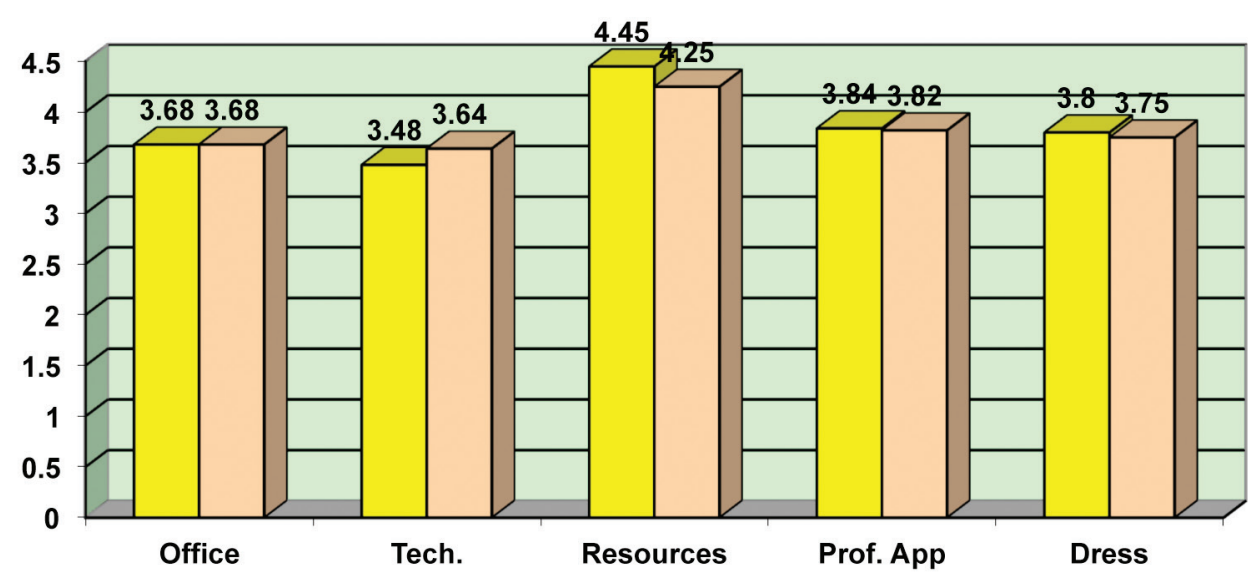

口Expectation

口Perception

Figure 1: Tangibles: Expectations versus perceptions

\section{Reliability: Expectations versus perceptions}

As indicated in Figure 2, customers being able to schedule a delivery easily was rated the highest expectation item, and trucks breaking down en route as the lowest expectation 
item. It would appear that breakdowns (despite being critical to effective service delivery) received a low expectation score because customers do not easily anticipate such an eventuality from a reputable transport company.

What is noteworthy, is the GAP score (1.0) on the issue of trucks breaking down en route. Although rated as having the lowest expectation, the perception on this item ranked the lowest in this dimension. Also, satisfying customer requests the first time indicates a substantial gap (0.955), followed by ability to schedule a delivery easily (0.5).

The smallest gap concerned the company's website being error free. The largest gap pertained to trucks arriving at their destination on time (GAP score $=2.0$ ). The magnitude of the difference between expectations and perceptions for this item is substantial.

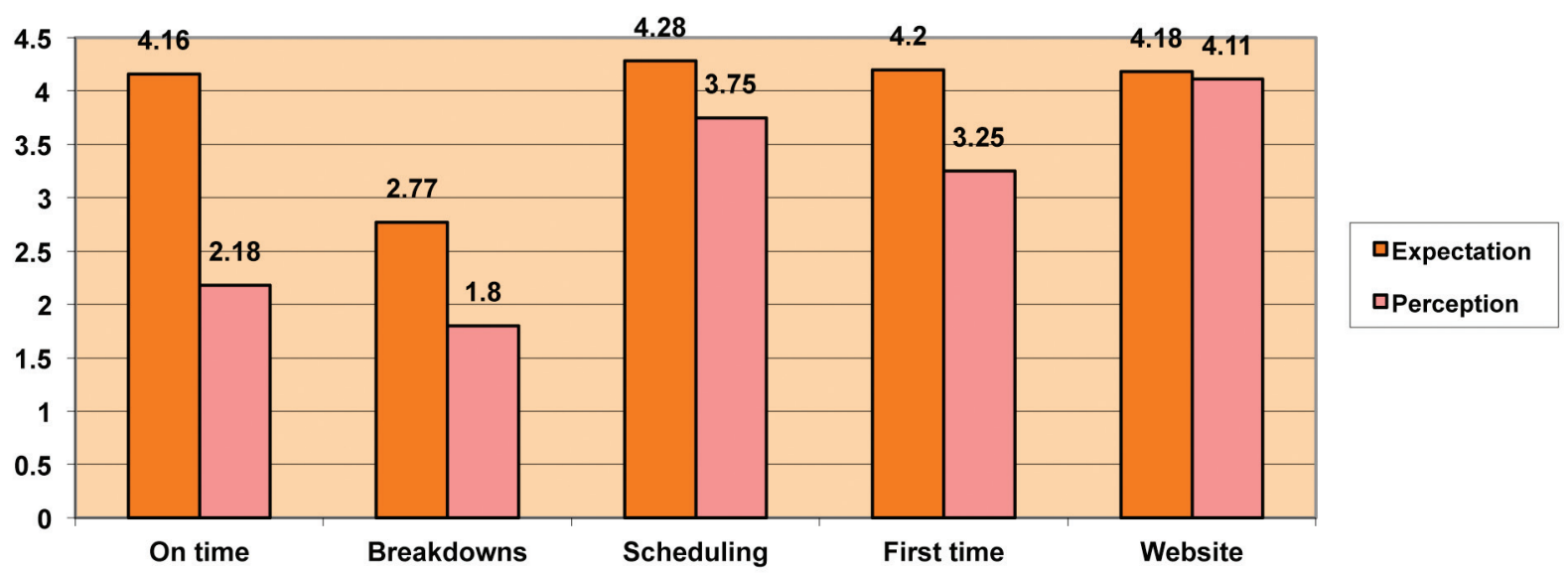

Figure 2: Reliability: Expectations versus perceptions

\section{Responsiveness: Expectations versus perceptions}

The results, as presented in Figure 3 indicate that the highest expectation was for timely and efficient service, with the lowest expectation applying to the item 'staff providing complete answers when attending to queries'.

The GAP scores, when comparing expectations with perceptions for each item were 1.6 (timely and efficient service), 1.12 (clear and helpful communication), 1.0 (providing complete answers) followed by the willingness of staff to help customers (0.58) and keeping customers informed of changes to timetables (schedules) and prices (0.5).

Clearly, all items for the responsiveness dimension exhibited relatively large GAP scores between expectations and perceptions. 


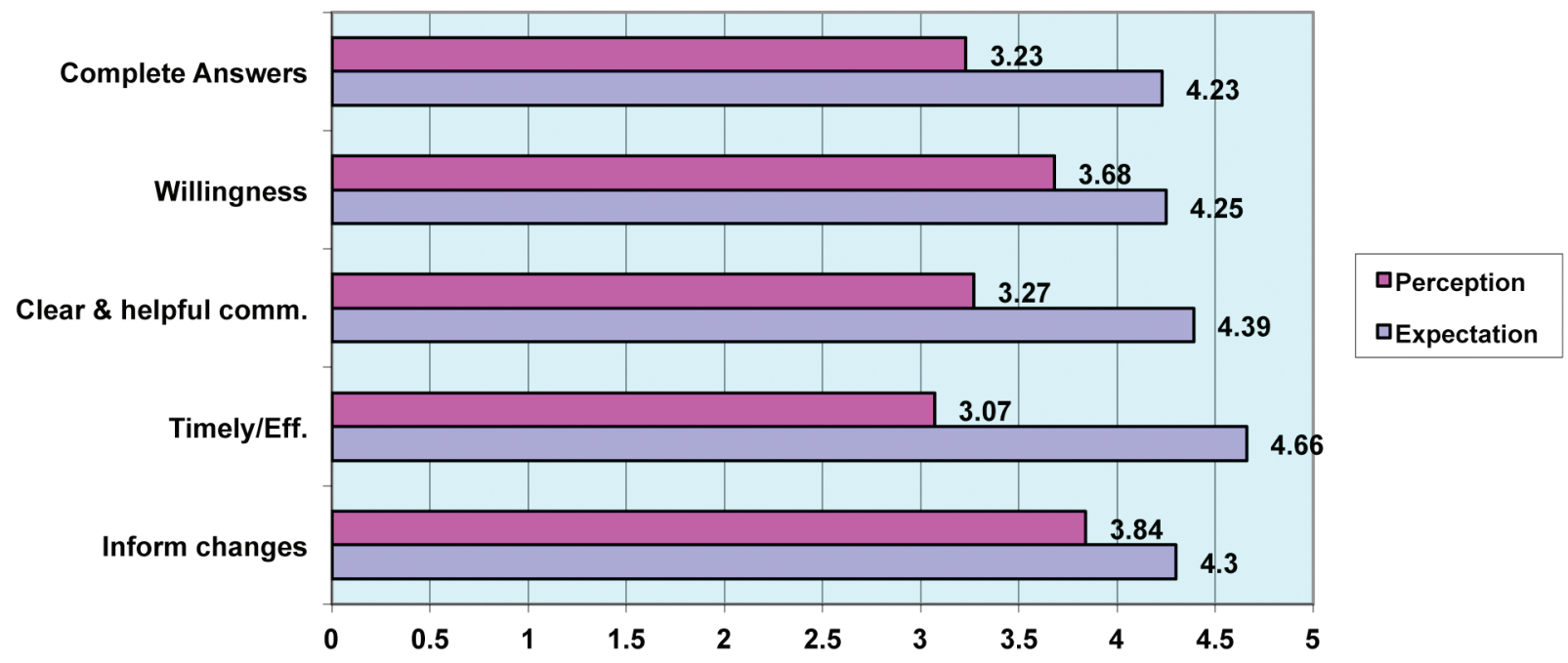

Figure 3: Responsiveness: Expectations versus perceptions

\section{Service quality dimensions: Expectations versus perceptions}

The results, as reflected in Figure 4, indicate that responsiveness was scored as the highest expectation dimension, followed by reliability and tangibles.

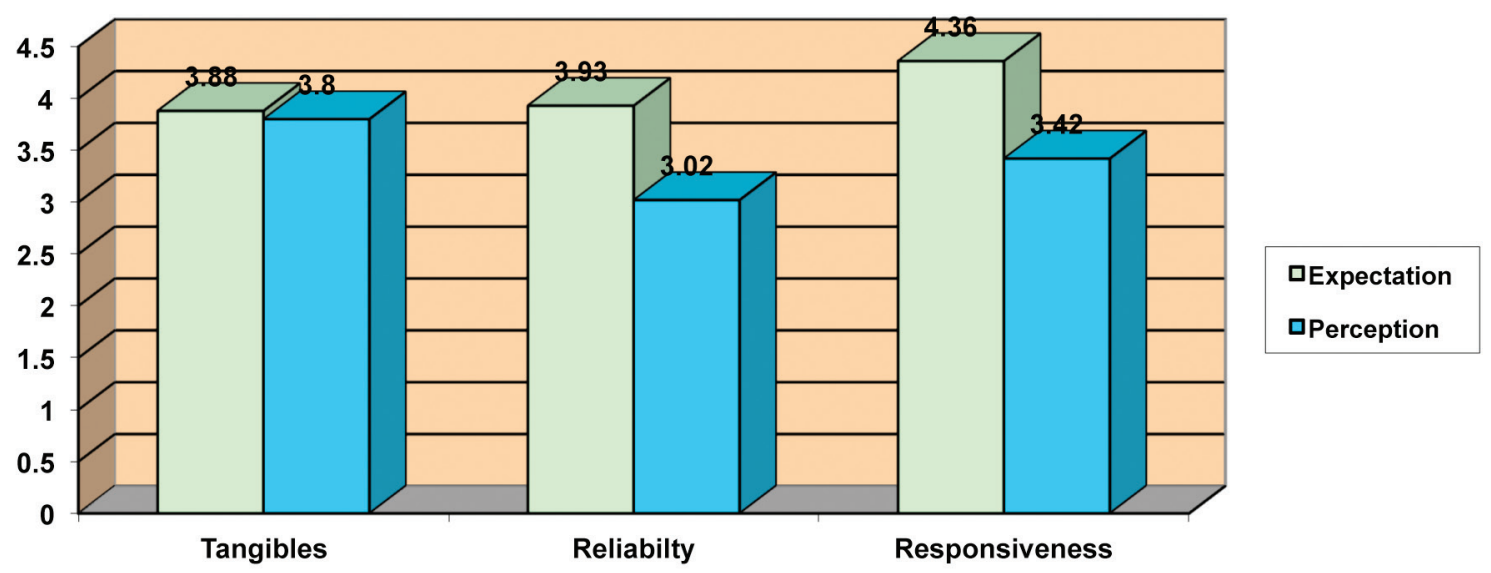

Figure 4: Service quality dimensions: Expectations versus perceptions

\section{SERVQUAL GAP scores}

This section intends to highlight the highest and lowest GAP scores.

The five highest GAP scores in terms of expectations and perceptions were:

- trucks arriving at their destination on time (1.977)

- providing timely and efficient service (1.591)

- clear and helpful communication (1.114)

- providing complete answers during customer queries (1.000)

- trucks breaking down en route (0.977) 
The five lowest GAP scores in terms of expectations and perceptions were:

- company having an attractive office (0.000)

- company having a professional appearance (0.023)

- dress of staff being neat and smart (0.045)

- information on company's website being error free (0.068)

- company staff members providing individual attention to customers (0.091)

A profile of the expectations and perceptions of the service quality dimensions as well as the rankings are presented in Table 2. The SERVQUAL GAP scores for each dimension are represented by their values in the P-E column.

The responsiveness dimension reflects the highest GAP score (0.94) implying that it needs to be accorded the highest priority with regard to the improvement of service quality, followed by reliability, assurance and empathy, with tangibles having the lowest priority. The mean GAP score of 0.55 indicates that the perceptions of respondents do not meet with their expectations of overall service quality in the industry.

Table 2: SERVQUAL GAP scores

\begin{tabular}{|l|c|c|c|c|}
\hline Dimension of service quality & Expectation (E) & Perception (P) & Score (P-E) & Rank \\
\hline Tangibles & 3.88 & 3.80 & 0.08 & 3 \\
\hline Reliability & 3.92 & 3.01 & 0.91 & 2 \\
\hline Responsiveness & 4.36 & 3.42 & 0.94 & 1 \\
\hline
\end{tabular}

\section{Inter-correlations among the service quality dimensions}

An inter-correlation analysis was carried out and the results indicated the following significant correlations (at the $95 \%$ level of significance):

- a weak, positive correlation between tangibles and reliability $(r=0.397 ; p=0.008)$

- a moderate, positive correlation between tangibles and responsiveness ( $r=0.459 ; p=0.002$ )

- a strong, positive correlation between reliability (expectations) and reliability (perceptions) $(r=0.660 ; p=0.000)$

- a strong, positive correlation between reliability and responsiveness $(r=0.704 ; p=0.000)$

\section{Hypothesis testing}

Four hypotheses were developed. These are discussed and empirically tested. 


\section{The expectations dimension and industry}

- Null hypothesis ( $\mathrm{HO})$ : There is no significant difference between the expectations of customers with regard to the service quality dimensions and industry.

- Alternate hypothesis ( $\mathrm{H} 1)$ : There is a significant difference between the expectations of customers with regard to the service quality dimensions and industry.

Table 3: ANOVA - Expectations and industry

\begin{tabular}{|l|l|l|}
\hline Dimension of service quality & F statistic & P \\
\hline Tangibles & 1.835 & 0.172 \\
\hline Reliability & 0.302 & 0.741 \\
\hline Responsiveness & 1.707 & 0.194 \\
\hline
\end{tabular}

Based on the analysis, as presented in Table 3, the null hypothesis is accepted. It can therefore be concluded that there is no significant difference between the expectations of customers with regard to the service quality dimensions and industry.

\section{The perceptions dimension and industry}

- Null hypothesis ( $\mathrm{HO})$ : There is no significant difference between the perceptions of customers with regard to the service quality dimensions and industry.

- Alternate hypothesis ( $\mathrm{H} 1)$ : There is a significant difference between the perceptions of customers with regard to the service quality dimensions and industry.

Table 4: ANOVA - Perceptions and industry

\begin{tabular}{|l|l|l|}
\hline Dimension of service quality & F statistic & P \\
\hline Tangibles & 0.252 & 0.778 \\
\hline Reliability & 0.118 & 0.889 \\
\hline Responsiveness & 0.265 & 0.769 \\
\hline
\end{tabular}

Based on the analysis, as presented in Table 4, the null hypothesis is accepted. It can therefore be concluded that there is no significant difference between the perceptions of customers with regard to the service quality dimensions and industry.

\section{Recommendations}

Based on the findings of the empirical study, the following recommendations are made:

- Vehicles should arrive punctually at their destination. Provision should be made for delays due to factors such as administration, loading, traffic jams and law enforcement. 
It is better to 'underpromise', i.e. give a later expected time than anticipated, than have the consignment arrive later than scheduled.

- Timely and efficient service should be provided. In this regard, staff training is important. Also, the workload of staff members, especially those in the front line, should be such that all customers are given prompt and full attention.

- The communication system should ensure that customers are provided with clear and helpful communication, as well as being furnished with complete answers during customer queries. The communication network should ensure a closer interface between the customer, staff member, truck driver, officials (e.g. customs staff) as well as management at the company. To this end, a more efficiently managed tracking system is advised, so that the status of deliveries can be closely monitored and reported.

- Preventive and routine maintenance should be rigorous in an attempt to reduce the number of truck breakdowns en route. Where breakdowns are driver related, training and/or disciplinary interventions may be necessary. The down time (repair period) should be as short as possible if repairs need to be conducted on site. Where possible, substitute trucks should be dispatched to ensure that the consignment reaches its destination as soon as possible.

- The communication and administration system should ensure that customer requests are satisfied the first time. A formal and efficient logging and tracking system together with clear accountability by front-line staff is advised.

- Staff members at all levels, particularly those who interact with customers, should be formally trained and placed under mentorship to ensure that these individuals have an in-depth knowledge of their jobs, in order to satisfy the diverse customer needs. This includes human relations, politeness and courtesy, crisis handling, finding creative solutions to problems and personal initiative when it comes to dealing with customers. The customer's best interests should be served.

- An incentive scheme should be introduced, rewarding staff members who have attained specified customer satisfaction levels. This can be facilitated by means of regular feedback being solicited from customers.

- Overall, a culture of customer orientation, across the organisation, should be inculcated.

\section{CONCLUSION}

This paper seeks to analyse service quality in the Durban freight transportation industry in the context of the intense competition within this sector. The concept of service quality is examined. The dimensions of service quality were identified and a GAP analysis conducted. It is clear that there is relationship between service quality and customer satisfaction. Five hundred questionnaires, based on the SERVQUAL model, were dispatched to active customers in the industry, of which 440 usable questionnaires were returned. The largest GAP score was for the responsiveness dimension, followed by the reliability and tangibles 
dimensions. It emerged that there were gaps between expectations and perceptions on 14 out of the 15 dimensions of service quality. The analysis revealed that there was no significant difference between the expectations and perceptions of customers with regard to the service quality dimensions and industry. The reliability measure indicated a high degree of internal consistency in the measuring instrument. Several recommendations have been presented as to how companies can narrow the gap between expected and perceived service quality. These centre around punctuality, clearer communication with customers, fleet maintenance, staff training and rewarding service excellence. The study was confined to the freight transportation industry in the Durban area. Findings may not necessarily be generalised to other regions or sectors of the transportation industry. 


\section{REFERENCES}

Becket, N. \& Brookes, M. 2006. Evaluating quality management in university departments. Quality Assurance in Education. 14(2):123-42.

Blose, J.E. \& Tankersley, W.B. 2004. Linking dimensions of service quality to original outcomes. Managing service quality. 14(1):75-89.

Brink, A. \& Berndt, A. 2005. Customer Relationship Management and Customer Service. Lansdowne: Juta \& Co. Ltd.

Bruhn, M. \& Georgi, D. 2006. Services marketing: managing the service value chain. London: Pearson Education Limited.

Dale, B.G. 2003. Managing quality. 4th ed. Blackwell Publishing: Oxford.

Dhurup, M., Singh, P.C. \& Surujlal, J. 2006. Customer service quality at commercial health and fitness centres. South African Journal for Research in Sport. 28(2):39-54.

Ekinci, Y. 2004. An investigation of the determinants of customer satisfaction. Tourism analysis. 8:197-203.

Fen, Y.S. \& Lian, K.M. 2007. Service quality and customer satisfaction: Antecedents of customers' re-patronage intentions. Sunway Academic Journal. 4:59-72.

Harris, E.K. 2003. Customer service. A practical approach. 3rd ed. New Jersey: Prentice-Hall. Jaiswal, A.K. 2008. Customer satisfaction and service quality measurement in Indian call centres. Managing Service Quality. 18(4):405-16.

Kotler, P., Bowen, J.T., Makens, J.C. 2006. Marketing for Hospitality \& Tourism. 4th ed. New Jersey: Pearson Prentice Hall.

Malhotra, N. 2010. Marketing Research: An applied orientation. 6th ed. New Jersey: Pearson.

Mullins, J.W., Walker Jr, O.C., Boyd Jr, H.W. \& Larreche, J. 2005. Marketing management: A strategic decision-making approach. New York: McGraw-Hill Irwin.

Pallant, J. 2007. SPSS Survival Manual - A step by step Guide to Data Analysis using SPSS for Windows. 3rd ed. New York: McGraw-Hill. 
Putruzellis, L., D'Ugento, M.A. \& Romanazzi, S. 2006. Students' satisfaction and quality of service in Italian universities. Managing service quality. 16(4):349-64.

Shiu, E., Hair, J., Bush, R. \& Ortinau, D. 2009. Marketing research. London: McGraw-Hill.

Van der Wal, R. W. E., Pampalis, A. \& Bond. 2002. Service quality in a telecommunications company: A South African experience. Managing Service Quality. 12(5):223-35.

Wang, Y., Hing-Po, L., \& Yang, Y. 2004. An Integrated Framework for Service Quality, Customer Value, Satisfaction: Evidence from China's Telecommunications Industry. Information Systems Frontiers 6(4) Available online: http//:dl.acm.org/citation.cfm [Accessed 23 February 2011].

Woo, K. \& Ennew, C.T. 2005. Measuring business-to-business professional service quality and its consequences. Journal of Business Research. 58:1178-85.

Zeithaml, V.A., Bitner, M. \& Gremler, D. 2006. Services marketing: Integrating customer focus across the firm. 4th ed. New York: McGraw-Hill Irwin. 